\title{
Description of Midwife Anxiety Levels in Antenatal Care Services during the COVID-19 Pandemic
}

\author{
Viona Delia Angelita ${ }^{1}$ Euvanggelia Dwilda ${ }^{2 *}$ Pirlina Umiastuti ${ }^{1,3}$ \\ ${ }^{1.2}$ Department of Midwifery Education, Faculty of Medicine University Airlangga 60132, Surabaya, East Java, Indonesia \\ ${ }^{3}$ Department of Public Health. Faculty of Medicine University Airlangga 60132, Surabaya, East Java, Indonesia
}

Corresponding Author : euvanggelia.dwilda@fk.unair.ac.id

\begin{abstract}
Background: The emergence of the Coronavirus Disease 2019 (COVID-19) outbreak has become the most important problem and challenge for the world health organization and the Indonesian government and throughout the world. Pregnancy services, namely Antenatal Care, are one of the services that are affected both in terms of access and quality. As health workers who are at the forefront in providing maternal and neonatal services, midwives cannot be separated from the risk of exposure to COVID-19 so that there is anxiety if they can get infected. Various government efforts in seeking medical personnel to get protection from contracting the COVID-19 virus, but anxiety cannot be avoided by someone. This study aims to describe the level of anxiety of midwives when providing Antenatal Care services during the COVID-19 pandemic. This type of research uses a quantitative descriptive design with 59 respondents, namely midwives using a random sampling technique. The analysis used is univariate. The results showed that most of the anxiety levels of midwives in Antenatal Care services were mild anxiety but there was also moderate to severe anxiety.
\end{abstract}

Keywords: Anxiety, Midwife, Antenatal Care, COVID-19

\section{Introduction}

The emergence of an outbreak of Coronavirus Disease 2019 (COVID-19) caused by a new virus, namely Severe Acute Respiratory Syndrome (SARS-CoV-2) occurred at the end of 2019 (Dong et al., 2020). Until the World Health Organization (WHO) announced on March 12, 2020, COVID-19 was a pandemic. Based on Worldometers data, as of March 16, 2021, there were 120,745,239 cases of COVID-19 worldwide. Transmission of the SARS-CoV-2 virus occurs from human to human through respiratory droplets. This disease becomes very lethal if there are complications of pneumonia and ARDS (Acute Respiratory Distress Syndrome) in severe cases rapidly and progressively worsening, such as ARDS, septic shock, metabolic acidosis that is difficult to correct and bleeding or coagulation system dysfunction within a few days. (POGI 2020)

Even during the COVID-19 pandemic, health development programs in Indonesia still prioritize efforts to improve maternal and child health in reducing morbidity and mortality. Efforts to reduce MMR and IMR should have been prepared since the antenatal period. However, Antenatal Care (ANC) midwifery care services need 
to be provided by paying attention to service standards and adjustments to health protocols that apply during the COVID-19 pandemic (ACOG, 2019). Facing this critical situation, the role of midwives is directly involved in the diagnosis, treatment, and care of pregnant women, including mothers suspected of being infected with COVID-19, so that midwives are at risk of experiencing psychological stress and mental health symptoms.

According to the IASC (2020) the causes of health workers experiencing anxiety are high job demands, increasing number of patients, community stigma, limited PPE, and lack of knowledge of health service guidelines in accordance with applicable health protocol standards. Kusumawati (2020) states that a person's anxiety is a condition in which feelings of worry, anxiety, restlessness, restlessness, anxiety arisecomfortable, so that it can cause physical and psychological complaints experienced by individuals against something that is considered a threat. Midwifery services in Antenatal Care in the pandemic era refer to the guidelines and principles of COVID-19 management that have been set by the government (Ministry of Health 2020).

The midwife's anxiety when conducting Antenatal Care examinations on the grounds that the client is dishonest if he has symptoms or is infected with COVID-19, besides that the midwife must also have direct contact with the mother. The emergence of anxiety can be influenced by environmental factors that can threaten him, negative emotions and thoughts, as well as physical symptoms he experiences (Saifudin, 2015).

Complaints felt by health workers usually arise because of the fear of transmitting COVID-19 to friends and family because of their field of work (IASC, 2020). The prevalence of depression, anxiety and insomnia among health workers during the COVID-19 pandemic was found to be quite high. A high level of anxiety can affect the quality of providing health services to patients, if the quality of these services decreases, it will have an impact on the level of success in prospering with good health for the community.

\section{Methods}

This study uses a quantitative descriptive method. The sample of this study was midwives who worked at the Surabaya Public Health Center using random sampling technique in sampling as many as 59 respondents. This research was conducted by taking data from respondents who served at the Surabaya Health Center. Data collection tools used were demographics and anxiety questionnaires (Stress and Anxiety to Viral Epidemics-9). The researcher used univariate analysis to get a description of the distribution of the demographic characteristics of the respondents (age, education and length of work) to see a picture of the anxiety level of midwives in providing Antenatal Care services during the COVID-19 pandemic.

\section{Result}

Respondents in this study amounted to 59 midwives who actively provide Antenatal Care services. The following table illustrates an overview of the characteristics of the midwives who became research respondents: 
Table 1. Characteristics of Midwives

\begin{tabular}{llll}
\hline Characteristics & & $\mathrm{n}$ & $\%$ \\
\hline Age & $20-30$ years old & 20 & 33.9 \\
& $31-40$ years old & 35 & 59.3 \\
\multirow{3}{*}{ Education } & $>40$ years & 4 & 6.8 \\
& DII & 1 & 1.7 \\
& DIII & 44 & 74.6 \\
Length of working & DIV/S1 & 14 & 23.7 \\
& S2 & 0 & 0 \\
& $1-5$ years & 23 & 39.0 \\
& $6-10$ years & 14 & 23.7 \\
& $>10$ years & 22 & 37.3 \\
\hline
\end{tabular}

Based onTable 1 shows that the frequency distribution of the age characteristics of respondents is mostly 31-40 years old as many as 35 people $(59.3 \%)$. Furthermore, the characteristics of respondents based on education level, most of whom in this study were DIII, were 44 people $(74.6 \%)$. The characteristics of the respondents based on the length of work, most of the midwives had a working period of $1-5$ years as many as $23(39.0 \%)$

Table 2. Frequency Distribution of Midwife Anxiety Levels in Antenatal Care services during the COVID-19 pandemic

\begin{tabular}{lll}
\hline Characteristics & $\mathrm{n}$ & $\%$ \\
\hline Light & 31 & 52.5 \\
Currently & 19 & 32.2 \\
Heavy & 9 & 15.3 \\
Total & 59 & 100.0 \\
\hline
\end{tabular}

Based on table 2, it was found that most of the midwives experienced mild anxiety when providing Antenatal Care services during the COVID-19 pandemic as many as 31 (52.5\%). However, there are also midwives with a severe anxiety level of $9(15.3 \%)$.

Table. 3 Frequency Distribution of Age Characteristics with Anxiety Levels of Midwives in Antenatal Care services during the COVID19 pandemic

\begin{tabular}{lcccccccc}
\hline \multirow{2}{*}{ Age } & \multicolumn{9}{c}{ Anxiety Level } & \multicolumn{2}{c}{ Total } \\
\cline { 2 - 7 } & \multicolumn{2}{c}{ Mild Anxiety } & \multicolumn{2}{c}{ Moderate anxiety } & \multicolumn{2}{c}{ Severe Anxiety } & \multicolumn{2}{c}{} \\
\cline { 2 - 7 } & $\mathrm{n}$ & $\%$ & $\mathrm{n}$ & $\%$ & $\mathrm{n}$ & $\%$ & $\mathrm{n}$ & $\%$ \\
\hline $20-30$ & 9 & 15.2 & 19 & 32.3 & 3 & 5.0 & 31 & 52.6 \\
$31-40$ years & 7 & 11.9 & 11 & 18.6 & 1 & 1.8 & 19 & 32.2 \\
old & 4 & 6.8 & 5 & 8.4 & 0 & 0 & 9 & 15.2 \\
$>41$ years old & 40 & 33.9 & 35 & 59.3 & 4 & 6.8 & 59 & 100 \\
Total & 20 & & & & & &
\end{tabular}


From table 3, it is found that most of the respondents' ages are 31-40 years old as many as 19 people (32.2\%) with the most anxiety level experienced by midwives in providing Antenatal Care services during the COVID19 pandemic, namely experiencing moderate anxiety as many as 11 people $(18.6 \%)$.

Table 4. Frequency Distribution of Educational Characteristics with Midwife Anxiety Levels in Antenatal Care services during the COVID19 pandemic

\begin{tabular}{lcccccccc}
\hline \multirow{2}{*}{$\begin{array}{l}\text { Length of } \\
\text { working }\end{array}$} & \multicolumn{9}{c}{ Anxiety Level } & \multicolumn{2}{c}{ Total } \\
\cline { 2 - 7 } & \multicolumn{2}{c}{ Mild Anxiety } & \multicolumn{2}{c}{ Moderate anxiety } & \multicolumn{2}{c}{ Severe Anxiety } & & \\
\hline DII & 0 & 0 & 1 & 1.7 & 0 & 0 & 1 & 1.7 \\
DIII & 26 & 44.0 & 13 & 22.0 & 5 & 8.5 & 44 & 74.5 \\
DIV/S1 & 5 & 8.5 & 5 & 8.5 & 4 & 6.8 & 14 & 23.5 \\
S2 & 0 & 0 & 0 & 0 & 0 & 0 & 0 & 0 \\
Total & 31 & 52.5 & 19 & 32.2 & 9 & 15.3 & 59 & 100 \\
\hline
\end{tabular}

From table 4, it is found that most of the respondents' education was DIII-year education as many as 44 people $(74.5 \%)$ with the most anxiety level experienced by midwives in providing Antenatal Care services during the COVID-19 pandemic, namely experiencing mild anxiety as many as 26 people $(44,0 \%)$.

Table 5. Frequency Distribution of Length of Work Characteristics with Midwife Anxiety Levels in Antenatal Care services during the COVID-19 pandemic

\begin{tabular}{lcccccccc}
\hline \multirow{2}{*}{$\begin{array}{c}\text { Length of } \\
\text { working }\end{array}$} & \multicolumn{9}{c}{ Anxiety Level } & \multicolumn{2}{c}{ Total } \\
\cline { 2 - 7 } & \multicolumn{2}{c}{ Mild Anxiety } & \multicolumn{2}{c}{ Moderate anxiety } & \multicolumn{2}{c}{ Severe Anxiety } & & \\
\cline { 2 - 7 } & $\mathrm{n}$ & $\%$ & $\mathrm{n}$ & $\%$ & $\mathrm{n}$ & $\%$ & $\mathrm{n}$ & $\%$ \\
\hline $1-5$ yrs & 13 & 22.0 & 6 & 10.2 & 4 & 6.8 & 23 & 39 \\
$6-10$ yrs & 5 & 8.5 & 7 & 11.9 & 2 & 3.4 & 14 & 23.8 \\
$>10$ years old & 13 & 22.0 & 6 & 10.2 & 3 & 5.0 & 22 & 37.2 \\
Total & 31 & 52.5 & 19 & 32.3 & 9 & 15.2 & 59 & 100 \\
\hline
\end{tabular}

From table 5, it is found that most of the respondents' working hours are 1-5 years as many as 23 people (39\%) with the most anxiety level experienced by midwives in providing Antenatal Care services during the COVID19 pandemic, namely experiencing mild anxiety as many as 13 people $(22.0 \%)$.

\section{Discussion}

During the COVID-19 pandemic, the anxiety of the entire world population, especially medical personnel who are at the forefront of handling patient recovery. One of the things that very often causes anxiety and fear related to COVID-19 in midwives themselves are environmental factors, the availability of Personal Protective Equipment (PPE), Standard Operating Procedures that apply to the workplace, self-readiness in handling patients to factors originating from individual midwives. both physically and psychologically (emotionally). Mild anxiety that occurs in bidam is caused by midwives who already have good knowledge of information 
received about COVID-19, namely from various media, training, counseling, internet and webinars related to how to provide maternal and child health services by minimizing the transmission of COVID,

The results showed that most of the last education of health workers was the last DIII education, which was 74.5\%. The results of this study are in line with the research results of Diah Arruum, Salbiah and Muniati (2015) in which most of the last education of health workers was DIII (44.6\%). The description of the level of anxiety of health workers in dealing with patients during the COVID-19 pandemic shows that the results of research conducted on 59 respondents found that most of the anxiety levels experienced were mild anxiety. This is in line with the research by Fadli et al (2020) which showed that most of the anxiety levels of health workers working in hospitals obtained an anxiety level $(65.5 \%)$. Anxiety that occurs in health workers is caused by lack of social support,

\section{Conclusion}

Based on the results of the analysis and discussion, it was found that the description of the anxiety level of midwives when providing Antenatal Care services during the COVID-19 pandemic, it was concluded that most of the respondents experienced mild anxiety when providing Antenatal Care services to patients during the COVID-19 pandemic, but there were also midwives. with moderate to severe anxiety. It is important as a health worker who provides attention to mental health during the COVID-19 pandemic, good knowledge regarding COVID-19, modes of transmission and prevention, planning, the need for supporting personal protective equipment and establishing health protocols is important to do in overcoming the anxiety of midwives.

\section{Suggestions}

1. For Respondents

It is expected to be able to control the level of anxiety by implementing protocols, a good level of knowledge, the use of good personal protective equipment and being able to maintain a healthy lifestyle to prevent infection with the COVID-19 virus.

\section{For Institutions}

It is hoped that this data can be used as evidence of the potential that can cause anxiety levels in health workers. Institutions can provide information through seminars and training related to preventing COVID-19 infection to health workers in order to continue to provide optimal health services to the community.

\section{For the Next Researcher}

Subsequent research is to examine what anxiety factors can affect the quality of service to health workers

\section{Acknowledgments}

The author expresses his deepest gratitude to the midwives on duty at the Surabaya Public Health Center for being willing to be respondents in this study. The author would like to thank all those who have contributed to help the work of this article. 


\section{References}

Alim SA, Kibria SM, Islam MJ, Uddin MZ, Nessa M., Wahab MA, Islam MM Translation of DASS 21 into Bangla and validation among medical students. Bangladesh J. Psychiatry. 2017;28(2):67-70. doi:10.3329/bjpsy.v28i2.32740.

Susilo., et.al., (2020). Coronavirus disease 2019 : a review of the current literature coronavirus disease 2019 : a review of the current literature. Indonesian Journal of Internal Medicine, 7(1), 45-67. Retrieved from http://www.jurnalsehatdalam.ui.ac.id/index.php/jpdi/article/view/415

Coronavirus Resource Center; COVID-19 Dashboard by the Center for Systems Science and Engineering at Johns Hopkins University. Johns Hopkins University \& Medicine. 2020. Available athttps://coronavirus.jhu.edu.Accessed July 21,2020.

Panchal N, Kamal R, Orgera K, Cox C, Garfield R, Hamel L, Munana C, Chidambaram P. The Implications of COVID-19 for Mental Heat and Substance Use. Kaiser Family Foundation. 2020.https://www.kff.org/coronavirus-covid-19/issue-brief/the-implicationsof... Accessed June 2020

WHO. (2020b). The World Health Organization declared the coronavirus outbreak a Global Public Health Emergency. Retrieved from https://www.worldometers.info/coronavirus/

Wu, Y., Chen, C., \& Chan, Y. (2020). The outbreak of COVID-19 : An overview. Journal of the Chinese Medical Association, 83(3), $217-220$ 